\title{
A Confidencialidade das Informações dos Usuários nos Serviços de Saúde na Percepção de Estudantes e Preceptores de Enfermagem
}

\author{
Pereira, Juliana Guisardi; Burigatti, Juliane Cristina; Oliveira, Maria Amélia de \\ Campos
}

Escola de Enfermagem da USP — julianaguisardi@gmail.com

INTRODUÇÃO a confidencialidade das informações é um princípio ético que integra ao da preservação da autonomia dos usuários dos serviços de saúde. Trata-se de um princípio fundamental tanto na formação quanto na prática dos profissionais de saúde. OBJETIVO Identificar situações envolvendo a confidencialidade de informações na percepção de estudantes e preceptores de Enfermagem. MÉTODO Estudo de abordagem qualitativa. Foram realizadas entrevistas semiestruturadas com 10 preceptores e 10 estudantes de uma faculdade pública do estado de São Paulo. o material empírico resultante foi submetido à técnica de análise de discurso. o trabalho foi aprovado pelo Comitê de Ética em Pesquisa $n^{\circ}$ 450/10. RESULTADOS e DISCUSSÃO Situações de falta de preservação da confidencialidade ocorreram na relação entre a equipe de saúde, o usuário e a família. uma preceptora descreveu um caso de confidencialidade da informação à mãe de usuária adolescente com resultado positivo ao teste de gravidez. "... Neste caso, foi explicado para a mãe..., que a gente não poderia quebrar o sigilo naquela situação". Estudo realizado com 711 adolescentes universitários sobre o valor da confidencialidade na assistência a sua saúde, a exigência de maior ou menor privacidade dependeu essencialmente do motivo do atendimento1. Outras duas estudantes relataram como a falta de confidencialidade de informações são problemas rotineiros nos serviços de saúde: "A discussão de casos de pacientes em corredores, como diagnóstico, questões pessoais mesmo dos pacientes...". a confidencialidade também apareceu em relação à organização do serviço de saúde, conforme depoimento de uma preceptora: "Fizeram o diagnóstico de HIV positivo, ele tinha 20 anos e foi a única parceira sem preservativo...O exame veio, não é para acontecer, mas a gente recebeu o exame aberto, em mãos, tem que ter sigilo, de outros serviços..." a cisão entre as dimensões técnica e a ético-política acentua tensões internas e revela a "desumanização" e a "despersonificação" dos sujeitos envolvidos no trabalho em saúde, tanto os profissionais quanto os usuários2. CONCLUSÃO o estudo evidenciou que a falta de preservação da confidencialidade das informações dos usuários dos serviços de saúde ocorreu geralmente na relação entre a equipe de saúde, o usuário e a família, mas também apareceu em relação à organização do serviço de saúde. a integração da ética à técnica possibilita a qualificação nas organizações de saúde e a humanização do cuidado. REFERÊNCIAS 1Loch JA, Closet J, Goldim, JR. Privacidade e confidencialidade na assistência à saúde do adolescente: percepções e comportamentos de um grupo de 711 universitários. Rev Assoc Med Bras. 2007; 53(3): 240-6. 2Schraiber LB. no encontro da técnica com a ética: o exercício de julgar e decidir no cotidiano do trabalho em medicina. Interface Comun Saúde Educ. 1997;1(1):123-38.

Pereira, Juliana Guisardi; Burigatti, Juliane Cristina; Oliveira, Maria Amélia de Campos. A Confidencialidade das Informações dos Usuários nos Serviços de Saúde na Percepção de Estudantes e Preceptores de Enfermagem.. In: Anais do Congresso Internacional de Humanidades \& Humanização em Saúde [= Blucher Medical Proceedings, num.2, vol.1]. São Paulo: Editora Blucher, 2014. ISSN 2357-7282

DOI 10.5151/medpro-cihhs-10385 